\title{
BMJ Open Socioeconomic disparities in coverage of full immunisation among children of adolescent mothers in India, 1990-2006: a repeated cross-sectional analysis
}

\author{
Chandan Kumar, ${ }^{1}$ Prashant Kumar Singh, ${ }^{2}$ Lucky Singh, ${ }^{3}$ Rajesh Kumar Rai ${ }^{4}$
}

To cite: Kumar C, Singh PK, Singh $\mathrm{L}$, et al.

Socioeconomic disparities in coverage of full immunisation among children of adolescent mothers in India, 19902006: a repeated crosssectional analysis. BMJ Open 2016;6:e009768.

doi:10.1136/bmjopen-2015009768

- Prepublication history and additional material is available. To view please visit the journal (http://dx.doi.org/ 10.1136/bmjopen-2015009768).

Received 22 August 2015 Revised 30 March 2016 Accepted 15 July 2016

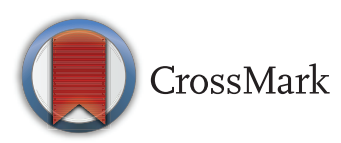

For numbered affiliations see end of article.

Correspondence to Dr Chandan Kumar; c.kumar803@gmail.com

\section{ABSTRACT}

Objective: Studies have highlighted that children of adolescent (aged 15-19 years) mothers are likely to receive relatively poor healthcare. With an unacceptably high adolescent birth rate, India houses the highest number of adolescent mothers globally, putting children at risk of inadequate vaccination. This paper assesses trends and extent of socioeconomic disparities in the coverage of full immunisation among children of adolescent mothers in India.

Design: Repeated cross-sectional analytical study. Data sources: 3 consecutive rounds of the National Family Health Survey (NFHS) conducted during 19921993, 1998-1999 and 2005-2006 were used. Besides, the required information is also extracted from the 2011 Indian Census.

Participants: Children (aged 12-23 months) of adolescent (aged 15-19 years) mothers. Sample inclusion criteria involved the last child of the adolescent eligible to avail full immunisation.

Setting: Nationally representative sample.

Data analysis: The Cochran-Armitage test, $\chi^{2}$ test and binary logistic regression methods were applied to attain the study objective.

Results: Between 1990 and 2006, a non-significant increase of 4 percentage points in full immunisation of children of adolescent mothers was estimated. During the same period, a large difference between the probability of children of adolescent mothers receiving full immunisation belonging to the least (predicted probability (PP): 0.196 in 1990-1993, and PP: 0.213 in 2003-2006) and the most (PP: 0.589 in 19901993, and PP: 0.645 in 2003-2006) socioeconomically privileged group was estimated, and this disparity persisted over the survey period.

Conclusions: During 1990-2006, an insufficient improvement in provision of full immunisation to children born to adolescent mothers was recorded. The study underscored the suboptimum immunisation of rural, illiterate and poor children of adolescent women. The programme and policymakers could focus on district-wise concentration of adolescent women, especially those belonging to the underprivileged groups, to design a targeted intervention to elevate the level of immunisation of children of adolescent mothers.

\section{Strengths and limitations of this study}

- This study draws attention to an important challenge in the ongoing efforts to improve reproductive and child healthcare services for adolescent mothers in India.

- Use of repeated cross-sectional surveys allows this study to assess the progress in coverage, and disparities in full immunisation across socioeconomic groups over one and half decades. However, unlike longitudinal surveys, this study provides its results based on the proportionate representation of select socioeconomic groups at different time periods.

- In the absence of relevant recent data, this study has limited its analysis to the period 2003-2006. However, the findings of this study would have long-term relevance, as it focuses on socioeconomic disparities, which have persistent influence in the behavioural aspects of healthcare services utilisation.

- This study mainly focuses on highlighting the plight of the children of adolescent mothers webbed into the interaction of the lowest categories of select socioeconomic parameters, and who could not be ignored as they represented more than a quarter of all children of adolescent mothers in India.

- On the technical front, this study acknowledges other important limitations such as the survey samples might not provide exact representation of each age-group of women across different socioeconomic groups. This could further be affected by specific selection of the child population in this study, and the recall errors of mothers (respondents of the survey).

\section{INTRODUCTION}

In 2011, nearly 22.4 million children globally were partially vaccinated at 12 months of age and remained at risk for vaccine-preventable morbidity and mortality. ${ }^{1}$ More than half of these incompletely vaccinated children were reported to be residing in three countries: India $(32 \%)$, Nigeria (14\%) and Indonesia 
(7\%). Immunisation with recommended vaccines at an early age for children is considered an essential component to reducing under-five mortality ${ }^{2-4}$ and childhood undernutrition. ${ }^{5}$ India continues to be one of the highest contributors of underweight children $^{6}$ and under-five mortality. ${ }^{7}$ Between 2004 and 2008, vaccinepreventable deaths in India were attributed to diphtheria (2000 deaths), tetanus (13000 deaths), pertussis (86 000 deaths), measles (81 275 deaths), hepatitis B (37 000 deaths), rotavirus (between $122000-153000$ deaths) and pneumonia (371 605 deaths). ${ }^{8}{ }^{9}$ Of the estimated 20.1 million infants who did not receive the first dose of measles-containing vaccine (MCV1) in 2011, 6.7 million (33\%) were reported in India. ${ }^{10}$ Notwithstanding, India has experienced a substantial reduction in estimated measles mortality during 20002011 and has achieved a milestone with its exclusion from the list of polio-endemic countries by the WHO in February 2012. ${ }^{11}$ Despite such limited achievements, around half of the children aged 12-23 months in India are devoid of access to all recommended vaccinations (based on a 2007-2008 nationally representative household survey). ${ }^{12}$

Realising the major setback in immunisation programmes, the current government has launched Mission Indradhanush in December 2014 as a special drive to vaccinate all unvaccinated and partially vaccinated children by 2020 under the Universal Immunisation Programme. ${ }^{13}$ In line with this government initiative, this study aims to draw attention towards a very important section of the population, that is, newborn children of adolescent mothers. With the spotlight turning to issues of adolescent pregnancy and their reproductive and child healthcare, ${ }^{14}$ the assessment of myriad socioeconomic and public health concerns related to adolescent mothers becomes an obligation for the research fraternity to contribute to this issue and enrich the public health literature.

\section{Why children of adolescent mothers?}

According to the 2011 Indian Census, more than 5 million children were born to adolescent mothers (aged 15-19) in India, probably the largest number of such births in South Asia. The implications for children of adolescents in this region are particularly serious, as 22 of the 100 girls in South Asia give birth by age 18, and 4 of these girls are 15 or younger. ${ }^{14}$ Unlike the children of older/physically matured women, the children born to adolescents are more prone to nutritional difficulties because of prematurity, undernutrition, inexperience and other medical complications faced by their mothers. ${ }^{15-18}$ The inadequate reproductive experience among adolescent mothers is also liable to be reflected in the postnatal care for their newborns. Separate estimates on access to full immunisation among children of adolescent mothers are limited; however, a few studies have shown that children of adolescent mothers (aged 15-19 years) often remain unvaccinated or partially vaccinated. ${ }^{19-21}$ In the Indian context, Singh $e t a l^{22}$ have assessed the access of full immunisation among children of adolescent mothers (aged 15-19) and examined associated factors. However, this study ${ }^{22}$ being limited to one survey period is not able to provide the progress in full immunisation among children of adolescent mothers and across different population groups.

Building on the existing literature and using three rounds of nationally representative data, the present study extends an assessment of full immunisation patterns and the extent of socioeconomic disparities among children of adolescents in India over time. It also elucidates the extent of disparity between the two extreme ends of the socioeconomic spectrum in rural and urban areas. The term socioeconomic spectrum is frequently used throughout this paper to refer to the interaction of select socioeconomic indicators such as education of mothers, social group or caste, place of residence and wealth quintile. Being at the disadvantageous end of these socioeconomic indicators (eg, being illiterate, belonging to a deprived social group or caste and in the lowest wealth quintile) is referred to as the least favoured group, while possessing the most advantageous mix of these indicators corresponds to the most favoured group.

\section{Socioeconomic disparity and child healthcare}

Three broad policy approaches to reducing health inequities can be identified as: (a) improving the health of the population belonging to the low socioeconomic position (SEP) groups through targeted programmes; (b) closing the health gaps between those in the poorest social circumstances and better off groups; and (c) addressing the entire health gradient, that is, the association between SEP and health across the whole population. ${ }^{23}$ In observing the ultimate impact of social processes on health equity, it is found that the structural factors associated with the key components of SEP are at the root of health inequities at the population level. This relationship is confirmed by a substantial body of evidence. ${ }^{24-29}$

In the Indian context, although health outcomes have improved with time, they continue to be strongly determined by factors such as gender, social or ethnic groups (caste), wealth, education and geography. ${ }^{30-35}$ In several contexts, socioeconomic inequalities in health appear to be widening rather than narrowing. ${ }^{36}$ In India, particularly young, poverty-affected women in rural areas are more vulnerable. ${ }^{37-40}$ Among various social factors, the level of maternal education is one of the key determinants of utilisation of healthcare services by their children. ${ }^{41-45}$ Mothers' education leads to better human, social and cultural capitals that then help increase immunisation rates for their children. ${ }^{46-57}$ Similarly, studies in India have long emphasised the relationship between maternal education, decision-making autonomy and greater utilisation of health services. ${ }^{58} 59$

Fathers' education is also regarded to be influential in regulating children's morbidity and mortality, ${ }^{60}$ and in 
providing their children better healthcare services including immunisation. ${ }^{61}$ Although studies have found mother's education more influential in children's health status, father's education acts as an important passive determinant of child healthcare status. There is evidence that the benefits of education of any member in the household may accrue to all. ${ }^{62}$

Another form of disparity in health outcomes or healthcare in India is in the inequities across different social groups or castes. Caste in India continues to represent social stratification, and is categorised in specific groups that are routinely used for population-based monitoring. These social groups are: Scheduled Castes (SC), Scheduled Tribes (ST), Other Backward Class (OBC), and other caste; the ST $(8 \%)$ and SC $(16 \%)$ are considered to be the most socially disadvantaged groups in India. ${ }^{63}$ The elimination of caste-based discriminatory practices and resulting socioeconomic inequalities has long been in the agenda of the Indian constitution, political insurgency and policies and programmes. However, caste-related disparities in some health aspects appear to remain high and show no signs of abating in parts of the country, ${ }^{64}$ while in a few health indicators, the absolute inequalities between caste groups have been observed increasing with time. ${ }^{65-67}$ Thus population-based studies (such as provision of basic amenities and services) in India recognise the caste/social group as an important socioeconomic indicator. ${ }^{31} 3968-70$

To some extent, such social stratification of Indian society also corresponds to the class ranking based on economic positions. A large number of studies have reported that society in India is becoming progressively unequal in terms of income distribution. ${ }^{71-74}$ The economic inequality has increased along several dimensions at the national level, between states, within states, within rural areas, within urban areas and between rural and urban areas. ${ }^{71}{ }^{75-77}$ Several recent studies have underscored the significant relationship between household economic status and child health in terms of mortality, ${ }^{78}$ morbidity, undernutrition ${ }^{34} \quad 79-82$ and utilisation of health services. ${ }^{83} 84$ The National Family Health Survey-3 (NFHS-3, 2005-2006) estimated that children (12-23 months old) in the wealthiest quintile were three times as likely as those in the poorest wealth quintile to receive all basic childhood vaccinations. ${ }^{65} 85$ This could be linked to the non-affordability of maternal and child healthcare among poorer households. ${ }^{86}$

Moreover, there is notable urban bias in public spending on healthcare and a known rural disadvantage in access to healthcare in India. ${ }^{87} 88$ Several studies in the Indian context have shown that rural inhabitants consistently reported being at a disadvantage in terms of service delivery. ${ }^{49-91}$ However, the immunisation coverage in urban India, although higher than in rural India, is also not universal. ${ }^{70}$ In many cases, the health of the urban poor is found to be worse than that of the rest of the urban population, and health conditions are often comparable to those of rural areas. ${ }^{92-94}$
All of the above major socioeconomic characteristics of the population are also supposed to influence each other in a way that the various endowed positive or negative characteristics would be compounded for the respective population, and widen the inequity in healthcare services. This study highlights such disparities in access to immunisation services resulting from the predisposed interaction of the pertinent SEPs of the adolescent women.

\section{METHODS}

\section{Study design}

The empirical and validated responses to satisfy the predisposed inquires in this study were established following an analytical framework based on the information available in the public domain. The required information was retrieved from three repeated cross-sectional surveys and a trend analysis was performed along with appropriate statistical models.

\section{Data}

This study is based on three rounds of NFHS data, which were collected during 1992-1993 (NFHS-1), 1998-1999 (NFHS-2), and 2005-2006 (NFHS-3) in India. ${ }^{65-67}$ NFHS is a standard cross-sectional large-scale survey in India, which provides nationally representative estimates on issues related to family welfare, maternal and child healthcare and nutrition at regular intervals. These surveys use a multistage cluster sampling design, and estimates can be compared by the sampling design. In NFHS-1, the information was collected from women for the previous three births in the 4 years preceding the survey date. Similarly, information was collected for the previous two births in the 3 years preceding the date of NFHS-2 (1998-1999). However, in NFHS-3 (2005-2006), information on antenatal care received by the women was collected only for the previous birth and information on assistance during delivery and immunisation for the previous three births in the 5 years preceding the date of the survey was collected. The individual response was $96.1 \%$ in NFHS-1, $95.5 \%$ in NFHS-2 and $94.5 \%$ in NFHS-3. The details of the sampling weights as well as extensive information on survey design, data collection and management procedures are described in the NFHS reports of the respective rounds. ${ }^{65-67}$ This study has also used aggregate data from the 2011 Indian Census.

\section{Study sample}

Considering the inconsistencies in the information collected across the three surveys, the study sample (ie, children aged 12-23 months who were liable to be immunised) was limited to information for the previous birth to adolescent mothers in the 3 years preceding the date of survey. The sample criteria included 4665 (NFHS-I), 4465 (NFHS-II) and 3034 (NFHS-III) samples in the study from the three rounds of the survey. The proportion of adolescent mothers (whose children were 


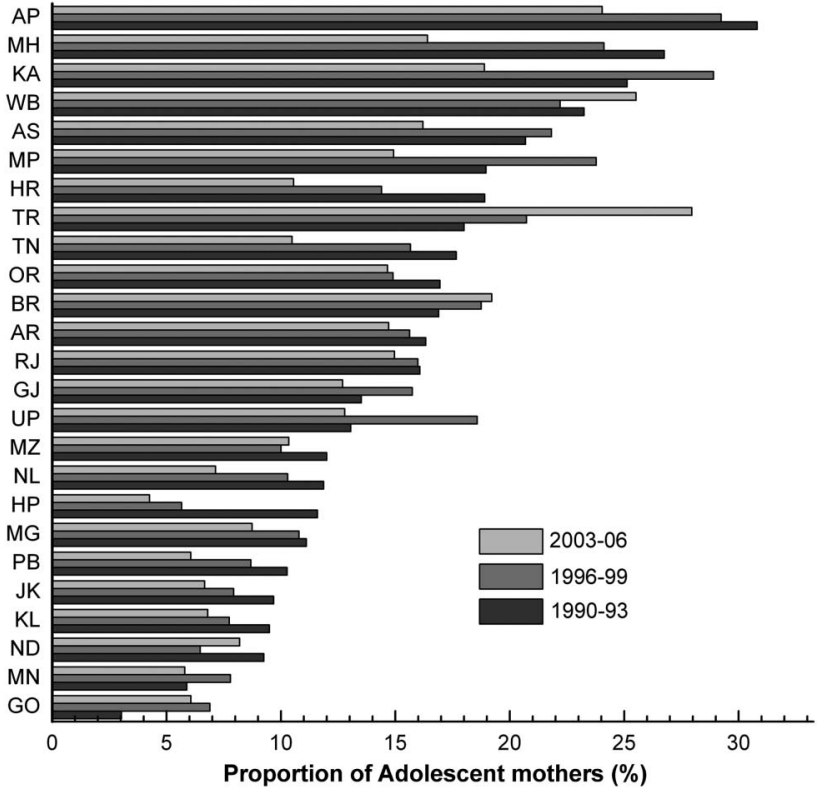

Figure 1 Proportion of adolescent mothers (whose children were included in the sample) out of all mothers in reproductive age by survey periods across states of India. AP, Andhra Pradesh; AR, Arunachal Pradesh; AS, Assam; BR, Bihar; GO, Goa; GJ, Gujarat; HR, Haryana; HP, Himachal Pradesh; JK, Jammu and Kashmir; KA, Karnataka; KL, Kerala; MG, Meghalaya; MH, Maharashtra; MN, Manipur; MP, Madhya Pradesh; MZ, Mizoram; ND, New Delhi; NL, Nagaland; OR, Orissa; PB, Punjab; RJ, Rajasthan; TN, Tamil Nadu; TR, Tripura; UP, Uttar Pradesh; WB, West Bengal.

included in the analysis) out of all mothers of reproductive age in states of India is presented in figure 1. The final analytic sample representing children of adolescent mothers in the 3 years preceding the date of the respective surveys by selected background variables is reported in online supplementary table S1. Data for the state of Sikkim were missing in NFHS-1, therefore in order to retain consistency samples from Sikkim in successive surveys were excluded. Appropriate sample weights as recommended by the NFHS data set were used in the analysis.

\section{Outcome measures}

'Adolescence' in this study refers to teenage motherhood, and the adolescent woman/mother is defined as an ever-married woman who has had the experience of childbirth in her teens (age 15-19) during the 3 years preceding the date of the respective surveys. The full immunisation of children (age 12-23 months) of adolescent mothers was assessed during the three successive survey periods stretching across one and half decades. According to the guidelines developed by the WHO (1998), children aged 12-23 months who received one dose each of Bacillus Calmette-Guérin (BCG) and measles, and three doses each of diphtheria, pertussis and tetanus (DPT) and polio vaccine, were defined as being fully immunised. ${ }^{95}$ The recommended immunisation schedule for children by age is presented in table 1 .

\section{Predictor variables}

The key socioeconomic predictors of interest that have prolific scope and influence in government policies and programmes include education of women/mothers and their husbands, social group, type of residence and household economic status. The selection of these variables is based on persistent factors of socioeconomic deprivation $^{96-98}$ as well as previous studies on adolescent maternity care. ${ }^{22}$ A woman's educational indicator was constructed based on information related to attainment of a particular level of education. This was categorised as: illiterate/no education; literate or below primary; primary; middle; and high school and above. A similar procedure was applied to construct the husband's education. The social group variable includes the following categories: SC, ST and 'Others'. In independent India, SC and ST are two historically socially disadvantaged groups who are given explicit recognition in the Constitution of India, and who constitute around 16\% and $8 \%$ of the population of India respectively, or around $24 \%$ altogether. In the context of socioeconomic disparities in India, the comparison of these two constitutionally recognised social groups with the relatively privileged population (observed as 'Others') becomes imperative from a public policy point of view. A household was classified according to the urban/rural definition of the Census of India. The level of economic status of women was derived from the information on household wealth vis-à-vis possession of wealth or assets by the household to which they belonged. In the absence of direct data on income in household sample surveys such as NFHS, a composite index of household wealth or asset is widely used as a surrogate indicator for assessing the economic status of the households. Several studies

Table 1 Recommended immunisation schedule for children in India

\begin{tabular}{|c|c|c|c|c|c|c|}
\hline Age (weeks) & Vaccine (months) & BCG & DPT & Polio & Measles & Cumulative coverage \\
\hline Birth & 0 & $\mathrm{x}$ & & & & BCG \\
\hline 6 & 1.5 & & $\mathrm{x}$ & $\mathrm{x}$ & & BCG+DPT 1+polio 1 \\
\hline 10 & 2.5 & & $\mathrm{x}$ & $\mathrm{x}$ & & BCG+DPT 1-2+polio 1-2 \\
\hline 14 & 3.5 & & $\mathrm{x}$ & $\mathrm{x}$ & & BCG+DPT 1-3+polio 1-3 \\
\hline 36 & 9.0 & & & & $\mathrm{x}$ & BCG+DPT 1-3+polio 1-3+measles \\
\hline
\end{tabular}

Source: Universal Immunisation Programme Division, Department of Family Welfare, Ministry of Health and Family Welfare. 
have found that the 'wealth index' highly correlates with income data in developing countries. ${ }^{99-101}$ The wealth index is computed using the principle of factor loading to household amenities, assets and durables derived by factor analysis. Based on the factor scores, households are categorised in quintiles (ie, five equal divisions, each representing $20 \%$ of the entire sample) from the poorest to the richest groups corresponding to the lowest to the highest quintiles at the national level. Thus, this study has represented the household economic status of women in terms of 'wealth quintile', categorised in five groups, that is, 'poorest', 'poorer', 'middle', 'richer' and 'richest'.

Other social and demographic variables were also used as covariates in the multivariate models, which include mother's age at childbirth ( $<18$ years, and 18-19 years); religion (Hindu, Muslim and others); work status (not working, working at home and working away from home); parity (1, 2, and 3+); birth order and interval (first birth order, birth order $2+$ and interval $\leq 24$ months, and birth order $2+$ and interval $>24$ months); sex of the child (male/female); mass media exposure (no exposure, and any exposure); desirable status of the child (wanted, and unwanted); and region of residence (north, central, east, northeast, west, and south). The desirable status of the child (whether 'wanted' or 'unwanted') for adolescent mothers was estimated from the difference between the number of living children to women and the ideal number of children they perceived. With the aim to capture the influence of the prior visits of adolescents to a healthcare facility, the utilisation of full antenatal care and professional attendance at delivery were also used as covariates in the multivariate model.

\section{Statistical analysis}

In order to trace the trend among children of adolescent mothers availing full immunisation over time, we assessed whether the association between the predictor of interest and the outcome variable varied by survey rounds. This required the data from all three rounds to be pooled and examined for the trend using linear or non-linear trend analysis. As the sampling design of the NFHS offers an opportunity to make all the three rounds of data comparable, several earlier studies have pooled the different rounds of NFHS datasets to observe changes over time. Prevalence estimates and 95\% CIs were calculated for adolescent women and their children (age 12-23 months) by the subgroups of key socioeconomic predictors using NFHS-calculated individual weights to take into account the multistage sampling design. Cochran-Armitage tests ${ }^{102}$ were used to test linear time-trend estimates, while $\chi^{2}$ tests were used for non-linear trends with tests adjusted for complex survey design. ${ }^{103}$

Since the outcome indicator used in this study was measured with a binary response in all surveys, we used a pooled multivariate logistic regression model to assess the influence or the strength of predictability of the selected socioeconomic predictors in accessing full immunisation by children of adolescent mothers. The multivariate model was adjusted for a set of sociodemographic factors. The results of the logit models are presented in terms of predicted probabilities with their $95 \%$ CIs. We additionally fitted a model stratified by survey periods and with interactions among key socioeconomic predictors to show the extent of inequality in the coverage of full immunisation among the children of adolescents belonging to different socioeconomic spectrum. The interactions between the predictor of interest and the survey rounds in the pooled data set were analysed using Wald tests. For unambiguous presentation of the logit model with number of interaction terms, we again report the results in terms of model-based predicted probabilities along with their 95\% CI. Analyses were performed using statistical software STATA V.10 (Statacorp . Stata statistical software: Release 10. College Station: Statacorp LP, 2007) and Microsoft Excel.

\section{RESULTS}

Table 2 shows the trends in the proportion of children (aged 12-23 months) of adolescent mothers availing full immunisation by their socioeconomic background. An increase of about four percentage points (13\%) was estimated from the level of 1990-1993 to 2003-2006. A substantial growth in the level of full immunisation was observed in the lowest three wealth quintiles and children of adolescent mothers belonging to the SC. The coverage of full immunisation among rural children was estimated to be 9\% higher in 2003-2006 from the period 1990-1993, while the increase in immunisation coverage among urban children of adolescent mothers was about 23\%. A considerable positive change in the immunisation coverage was also observed among children of uneducated adolescent mothers; however, there was no systematic pattern while comparing the prevalence of full immunisation among children of mothers and fathers with different levels of education.

After adjusting for selected sociodemographic and economic factors, there was no statistically significant positive change in the overall probability of children of adolescents availing full immunisation during 1990-1993 to 2003-2006 (table 3). However, the selected socioeconomic factors appeared to be significant determinants of the prevalence of full immunisation among children of adolescent mothers, thus suggesting considerable socioeconomic disparities in the immunisation coverage as hypothesised. The probability of children availing full immunisation appeared to be significantly higher with increasing economic level (ie, wealth quintile) of adolescent mothers. Mother's and father's education were non-linearly associated with the probability of availing full immunisation during 1990-2006. Social groups did not appear to wield statistically significant influence on the likelihood of children availing full vaccination. The children of adolescent mothers residing in rural areas were about $24 \%$ more likely to avail full immunisation compared with their urban counterparts. 
Table 2 Prevalence (\%) of children aged 12-23 months of adolescent mothers being fully immunised by socioeconomic characteristics, India, 1990-2006

\section{Full immunisation}

\begin{tabular}{|c|c|c|c|c|c|}
\hline $\begin{array}{l}\text { Socioeconomic } \\
\text { characteristics }\end{array}$ & NFHS-1 (1990-93) & NFHS-2 (1996-99) & NFHS-3 (2003-06) & $\begin{array}{l}\text { Relative } \\
\text { change }(\%)^{\star}\end{array}$ & $\begin{array}{l}\text { p Value } \\
\text { for } \\
\text { trendt }\end{array}$ \\
\hline \multicolumn{6}{|l|}{ Mother's education } \\
\hline Illiterate & 26.8 (23.9 to 30.0$)$ & 25.7 (22.5 to 29.2$)$ & 25.1 (21.1 to 29.7$)$ & -6.3 & $<0.001$ \\
\hline Literate or below primary & 45.8 (36.9 to 55.0 ) & 53.1 (43.8 to 62.2 ) & 43.9 (33.2 to 55.1$)$ & -4.3 & $0.382 \ddagger$ \\
\hline Primary & $51.4(44.7$ to 58.1$)$ & 48.3 (41.0 to 55.6$)$ & 48.4 (41.1 to 55.8$)$ & -5.8 & $0.798 \ddagger$ \\
\hline Middle & 58.4 (48.6 to 67.6$)$ & 52.4 (42.1 to 62.4$)$ & 59.3 (50.5 to 67.6$)$ & 1.7 & $0.553 \ddagger$ \\
\hline High school and above & 58.6 (47.9 to 68.4$)$ & $71.4(61.2$ to 79.8$)$ & 61.1 (50.9 to 70.5$)$ & 4.4 & $0.189 \ddagger$ \\
\hline \multicolumn{6}{|l|}{ Father's education } \\
\hline Illiterate & 24.4 (21.0 to 28.3 ) & 26.8 (22.3 to 31.8$)$ & 31.7 (25.8 to 38.2$)$ & 29.6 & 0.046 \\
\hline Literate or below primary & 37.4 (28.2 to 47.6$)$ & 33.1 (24.4 to 43.0$)$ & 37.2 (27.0 to 48.8 ) & -0.5 & $0.789 \ddagger$ \\
\hline Primary & 39.0 (32.9 to 45.3$)$ & 44.1 (37.9 to 50.5$)$ & 43.8 (36.6 to 51.3 ) & 12.5 & $0.468 \ddagger$ \\
\hline Middle & $47.4(40.8$ to 54.1$)$ & 41.1 (34.9 to 47.7$)$ & 38.7 (32.2 to 45.6 ) & -18.4 & 0.066 \\
\hline High school and above & 46.5 (41.5 to 51.6$)$ & 47.5 (41.5 to 53.6$)$ & 50.3 (43.3 to 57.4$)$ & 8.2 & 0.404 \\
\hline \multicolumn{6}{|l|}{ Social group } \\
\hline $\mathrm{SC}$ & 26.7 (20.6 to 33.7 ) & 39.1 (32.9 to 45.8$)$ & 37.6 (30.3 to 45.6$)$ & 41.2 & $0.037 \ddagger$ \\
\hline ST & 29.9 (23.8 to 36.9$)$ & 22.6 (16.2 to 30.6$)$ & 34.4 (26.0 to 43.9$)$ & 14.8 & $0.123 \ddagger$ \\
\hline Other than SC and ST & 38.2 (35.4 to 41.2 ) & 40.4 (36.7 to 44.2$)$ & 41.4 (37.1 to 45.8$)$ & 8.2 & $<0.001$ \\
\hline \multicolumn{6}{|l|}{ Wealth quintile } \\
\hline Poorest & 20.2 (16.5 to 24.5$)$ & 28.8 (23.8 to 34.4 ) & 29.5 (23.7 to 36.0 ) & 46.1 & 0.085 \\
\hline Poorer & 28.7 (23.6 to 34.5$)$ & 29.7 (25.2 to 34.5$)$ & 35.3 (28.9 to 42.2$)$ & 22.8 & 0.230 \\
\hline Middle & 35.1 (30.1 to 40.5$)$ & 45.4 (39.3 to 51.6$)$ & 45.9 (39.1 to 53.0 ) & 30.8 & 0.097 \\
\hline Richer & 56.3 (49.6 to 62.7$)$ & 56.6 (49.3 to 63.7$)$ & 49.1 (41.1 to 57.1$)$ & -12.8 & $0.268 \ddagger$ \\
\hline Richest & 56.4 (49.6 to 63.0$)$ & 53.1 (43.2 to 62.9$)$ & 60.6 (47.8 to 72.0$)$ & 7.4 & $0.648 \ddagger$ \\
\hline \multicolumn{6}{|l|}{ Area of residence } \\
\hline Rural & 34.8 (31.8 to 37.8 ) & 35.5 (32.1 to 39.0 ) & 37.8 (33.8 to 42.0 ) & 8.8 & $<0.001$ \\
\hline Urban & 40.4 (35.1 to 45.9 ) & 49.6 (42.8 to 56.5$)$ & 49.7 (42.5 to 56.9 ) & 23.1 & $<0.001$ \\
\hline Total & 35.7 (33.2 to 38.3$)$ & 38.0 (35.0 to 41.0$)$ & 40.3 (36.8 to 43.9$)$ & 12.8 & $<0.001$ \\
\hline
\end{tabular}

Figures in parentheses are $95 \%$ Cls for the proportions.

${ }^{*}$ Calculated as relative change $=(($ final period \%/period $1 \%)-1)$.

†Based on Cochran-Armitage time trend analyses using Rao-Scott adjustments to assess significant trends over time by socioeconomic characteristics.

$\ddagger \chi^{2}$ analyses with Rao-Scott adjustments were applied due to nonlinear trends over time by socioeconomic characteristics.

NFHS-1, National Family Health Survey-1; SC, Scheduled Castes; ST, Scheduled Tribes.

Children of rural adolescent mothers with no education in the poorest wealth quintile were $40-43 \%$ less likely to avail full immunisation compared with children of urban adolescent mothers with high school and above education in the richest wealth quintile during 1990-2006 (table 4). Similarly, the children of rural SC/ ST adolescent mothers with no education in the lowest two (poorest and poorer) wealth quintiles had 39-54\% less probability of availing full immunisation compared with children of urban SC/ST adolescent mothers with high school and above education in the highest two (richest and richer) wealth quintiles. However, the difference in probability between the children of SC/ST adolescent mothers in the lowest two quintiles residing in rural and urban areas was found negligible during the period.

\section{DISCUSSION}

This study provides evidence of persisting socioeconomic disparity in access to full immunisation among children of Indian adolescent mothers in the last one and half decades. It presents trends in childhood immunisation by key socioeconomic characteristics and shows wide disparity in availing full immunisation by children of adolescent mothers across select socioeconomic groups. The analysis is crucial from the programmatic point of view, as the findings of this study did not indicate a statistically significant improvement in access to full immunisation by the children of adolescent mothers during 1990-2006. Although, a separate analysis carried out to assess the immunisation status of children of older mothers (age $>19$ years) indicated a statistically significant improvement (see online supplementary table S2). Moreover, a wide disparity in access to full immunisation among children of adolescent mothers across the extreme ends of socioeconomic status was evident.

Findings showed that the difference in the probabilities of children availing full immunisation belonging to the most disadvantaged and advantaged mix of socioeconomic characteristics (based on their place of residence, education and economic status) was almost 
Table 3 Selected socioeconomic predictors for children (aged 12-23 months) of adolescent women accessing full immunisation, India, 1990-2006

\begin{tabular}{|c|c|c|}
\hline \multirow[b]{2}{*}{$\begin{array}{l}\text { Children aged } 12-23 \text { months } \\
(\mathrm{N}=4922)\end{array}$} & \multicolumn{2}{|l|}{ Full immunisation } \\
\hline & $\begin{array}{l}\text { Univariate analysis } \\
\text { PPt }(95 \% \mathrm{Cl})\end{array}$ & $\begin{array}{l}\text { Multivariate analysis }{ }^{*} \\
\text { PP¥ }(95 \% \mathrm{Cl})\end{array}$ \\
\hline \multicolumn{3}{|l|}{ Period } \\
\hline 1990-1993 & $0.357(0.332$ to 0.383$)$ & $0.287(0.244$ to 0.334$)$ \\
\hline 1996-1999 & $0.380(0.350$ to 0.410$)$ & $0.307(0.262$ to 0.356$)$ \\
\hline 2003-2006 & 0.403 (0.368 to 0.439$)$ & $\begin{aligned} & 0.353(0.303 \text { to } 0.407) \\
& p=0.339\end{aligned}$ \\
\hline \multicolumn{3}{|l|}{ Mother's education } \\
\hline Illiterate & $0.261(0.241$ to 0.281$)$ & $0.216(0.190$ to 0.244$)$ \\
\hline Literate or below primary & $0.479(0.422$ to 0.537$)$ & $0.342(0.312$ to 0.373$)$ \\
\hline Primary & $0.493(0.451$ to 0.535$)$ & 0.441 (0.409 to 0.474$)$ \\
\hline Middle & 0.570 (0.515 to 0.623$)$ & 0.545 (0.510 to 0.580$)$ \\
\hline High school and above & $0.635(0.575$ to 0.691$)$ & $\begin{array}{l}0.665(0.625 \text { to } 0.702) \\
p<0.001\end{array}$ \\
\hline \multicolumn{3}{|l|}{ Father's education } \\
\hline Illiterate & $0.269(0.243$ to 0.296$)$ & $0.200(0.174$ to 0.229$)$ \\
\hline Literate or below primary & $0.358(0.302$ to 0.418$)$ & $0.284(0.255$ to 0.316$)$ \\
\hline Primary & $0.421(0.383$ to 0.460$)$ & $0.333(0.303$ to 0.363$)$ \\
\hline Middle & 0.421 (0.383 to 0.461$)$ & $0.398(0.367$ to 0.430$)$ \\
\hline High school and above & $0.480(0.445$ to 0.515$)$ & $\begin{aligned} 0.541(0.504 \text { to } 0.578) \\
p=0.013\end{aligned}$ \\
\hline \multicolumn{3}{|l|}{ Social group } \\
\hline Other than SC and ST & $0.397(0.377$ to 0.418$)$ & $0.394(0.362$ to 0.427$)$ \\
\hline $\mathrm{SC}$ & 0.351 (0.311 to 0.393$)$ & $0.302(0.270$ to 0.335$)$ \\
\hline ST & 0.290 (0.248 to 0.336$)$ & $\begin{aligned} & 0.254(0.219 \text { to } 0.293) \\
& p=0.564\end{aligned}$ \\
\hline \multicolumn{3}{|l|}{ Wealth quintile } \\
\hline Poorest & $0.258(0.229$ to 0.289$)$ & $0.170(0.147$ to 0.197$)$ \\
\hline Poorer & $0.310(0.278$ to 0.343$)$ & $0.242(0.217$ to 0.270$)$ \\
\hline Middle & $0.416(0.381$ to 0.452$)$ & $0.354(0.325$ to 0.384$)$ \\
\hline Richer & 0.539 (0.497 to 0.582$)$ & 0.498 (0.464 to 0.533$)$ \\
\hline Richest & 0.566 (0.514 to 0.616$)$ & $\begin{aligned} & 0.612(0.572 \text { to } 0.650) \\
& p<0.001\end{aligned}$ \\
\hline \multicolumn{3}{|l|}{ Area of residence } \\
\hline Rural & $0.359(0.339$ to 0.379$)$ & $0.303(0.274$ to 0.333$)$ \\
\hline Urban & 0.462 (0.425 to 0.501$)$ & $\begin{aligned} & 0.491 \\
& p=0.072\end{aligned}$ \\
\hline
\end{tabular}

The $p$ Value refers to adjusted Wald test.

*Multivariate model controls for mother's age at childbirth, religion, work status of mother, parity, birth order and interval, mass media exposure of mother, desirable status of the child, utilisation of full antenatal care by mother, professional attendance at delivery and region of residence besides all variables shown in the table.

†Unadjusted predicted probability.

$\ddagger$ Adjusted predicted probability.

PP, predicted probability; SC, Scheduled Castes; ST, Scheduled Tribes.

twofold to threefold and such disparities were consistent over the survey period. The most deprived children in terms of receiving full immunisation appeared to reside in rural areas, belonged to poor families, and their mothers were illiterate. Interacting the impact of children belonging to socially deprived groups (ie, SC/ST) in association with their place of residence and economic status did not present much variation in probability, compared with the situation when the extreme ends of their mother's education was introduced in the socioeconomic spectrum. This experiment established the fact that economically poor children of illiterate adolescent mothers from rural areas, irrespective of the social groups they belonged to, were the most deprived groups of children in terms of availing full vaccination. Moreover, the improvement in their vaccination status was found insufficient. The analysis showed that this deprived group of children represented almost onefourth of all children born to adolescent mothers, thus neglecting these children could significantly obstruct India's efforts to combat child mortality due to communicable diseases.

Previous studies from India and other low and middle income countries have highlighted the importance of 


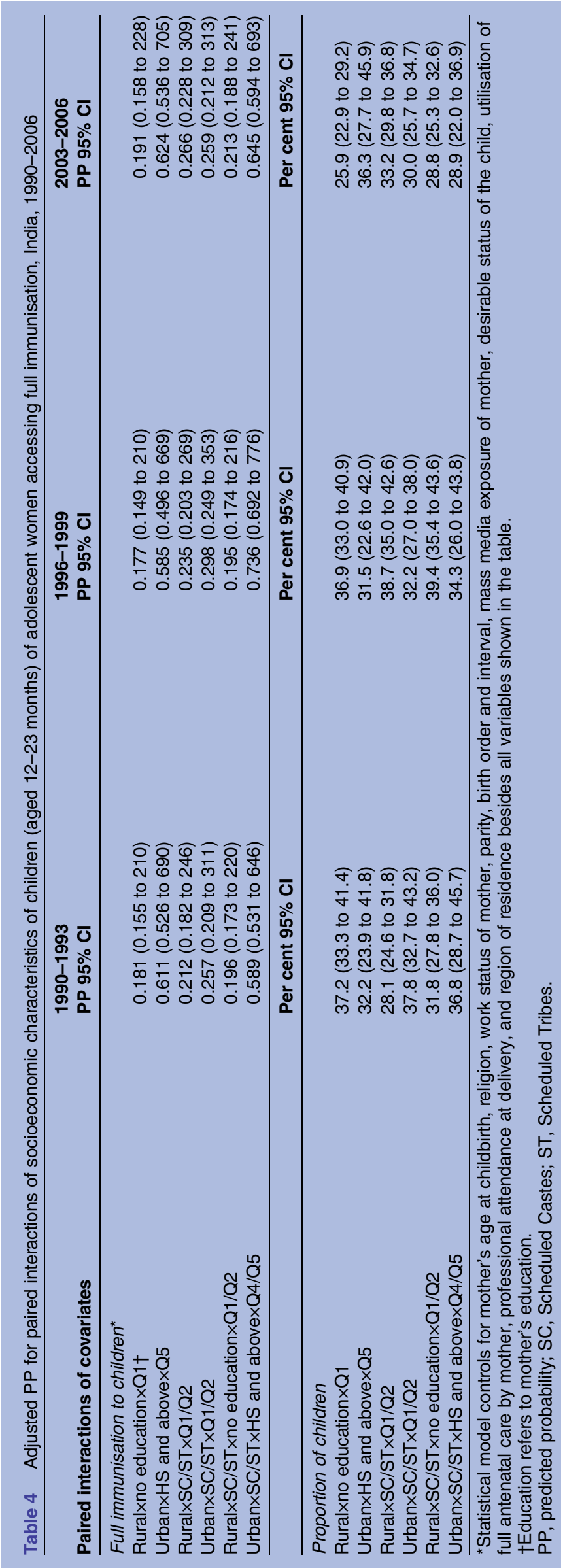

social determinants in child healthcare utilisation. ${ }^{104}$ For example, the rural disadvantage in utilisation of healthcare services over urban has been repeatedly emphasised in various studies. In contrast to urban areas, the utilisation of health services in rural areas is limited by factors associated with availability, accessibility and quality of services as well as the characteristics of the users and the communities in which they live. ${ }^{105}$ Specifically, geographical access has a greater impact on the utilisation of healthcare services, particularly in rural areas with limited provision of healthcare services. ${ }^{106}$ Similarly, the importance of women's education in healthcare utilisation has been one of the most discussed issues in the global public health debate, particularly in the context of child health in low and middle income countries. However, the effect of education on child healthcare utilisation is much more pragmatic for adolescent women than for older women. Lack of education coupled with reproductive inexperience makes adolescent mothers and their children vulnerable. Early marriages tend to curtail young women's educational attainment, ${ }^{22} 107$ as they are often expected to leave school after marriage in order to devote their time to homemaking and taking care of their children. ${ }^{108}$ There is a clear linear relationship between years of education and women's freedom of movement in the context of their visit to market, health facility and even places outside the village and community. ${ }^{65}$ For instance, as per the NFHS-3 report, nearly one in five women from the age group 15-19 were allowed to go to a health facility by their families, much lower than the women in the age group 20-24 (36\%), 25-29 (50\%) and 30-39 (60\%).

The economic status of the family is another key factor influencing childhood immunisation, which emerged in this study in the context of children of adolescent mothers. It is often argued that poor households do not have resources for healthcare expenses, as their priority is to meet basic daily needs, whereas wealthier households can spend a higher proportion of their earnings on healthcare. Low coverage of immunisation among children of adolescent mothers could be the result of their additional workload, providing economic support to the family and possible ignorance of child immunisation, highlighted by other studies in India ${ }^{6}$ and other resource-poor settings. ${ }^{109} 110$ Although, workforce participation among adolescent women has been found lower compared with their older counterparts. Moreover, of all the adolescent women who were engaged in the formal labour force, nearly $40 \%$ were not empowered to spend their earnings as per their wish. Rather, the decision to spend their earnings was largely dependent on their husband and other household members. ${ }^{65}$ This proportion was much lower for women of age-groups 20-24 (27\%), 25-29 (19\%) and 30-39 (14\%)..$^{65}$

Although the analyses carried out in this study are limited to the year 2006, the relevance of the findings could not be underestimated, as the estimates from a few later surveys such as District Level Household Survey 
(DLHS)-3 (2007-2008) ${ }^{12}$ and Annual Health Survey (AHS) (2012-2013) ${ }^{111}$ also indicate insufficient coverage in full-immunisation. Even the better performing states such as Uttarakhand, Chhattisgarh and Rajasthan fell short by 20-25 percentage points in achieving universal coverage as per the AHS estimates. Moreover, the focus of this study lies in highlighting the socioeconomic disparities in utilisation of full immunisation by a special group of population, which did not show adequate improvement over one and a half decades and likely to be persistent in near future too, if at all, the issue remained unaddressed.

\section{Policy implications}

Globally, monitoring inequalities in health is foremost in the agenda of public health surveillance. ${ }^{33}$ In 2012, Ministers of Health from 194 countries at the 65th World Health Assembly held in Geneva endorsed the Global Vaccine Action Plan (GVAP), a roadmap to prevent millions of deaths by 2020 through equitable access to vaccines for people in all communities. ${ }^{34}$ Addressing socioeconomic differences in health and encouraging equitable distribution of health services has been one of the prime goals of India's contemporary health policy. ${ }^{35}$ In order to achieve this goal, an assessment of health outcomes across space, time and groups is desirable. In this connection, the prime catch of this study concentrated on years-long persistence of disparities in the use of healthcare services across socioeconomic strata, which clearly suggests low priority in addressing social determinants of child immunisation over the select period. This also implies that the increase in average immunisation may not essentially assure universal and equitable coverage to all, and the reach of services is still confined to certain favoured sections of the population. Findings of the present study re-emphasised the need to prioritise vaccination among children born to adolescent women and to address the socioeconomic disparities in immunisation coverage under existing health programmes, including Mission Indradhanush. Further, focus must be on those adolescent mothers who are illiterate, poor and residing in rural areas. According to the 2011 Indian Census, Uttar Pradesh (18\%), West Bengal (13\%), Bihar (12\%), Maharashtra (7\%), Rajasthan (7\%), Madhya Pradesh (7\%) and Andhra Pradesh (7\%) shared almost $70 \%$ of all children born to adolescent women residing in rural areas (see online supplementary table S3). These states need to take concerted steps in the care of adolescent women and their children in terms of healthcare services including immunisation. In order to prioritise the programmatic efforts at the district level, this study has presented the district-wise proportion of adolescent women out of total women in reproductive age (figure 2A) and the proportion of rural, illiterate adolescent women who belong to socially deprived groups (ie, SC/ST) out of total rural women in reproductive age (figure 2B), as per the 2011 Indian Census. Bijapur and Dantewada (in Chhattisgarh), Malkangiri (in Odisha), Alirajpur, Jhabua and Burhanpur, Barwani (in Madhya Pradesh), Pratapgarh (in Rajasthan), Mon (in Nagaland) and Jaintia Hills (in Meghalaya) comprised a considerable proportion of rural, illiterate adolescent women who were from the socially deprived groups.
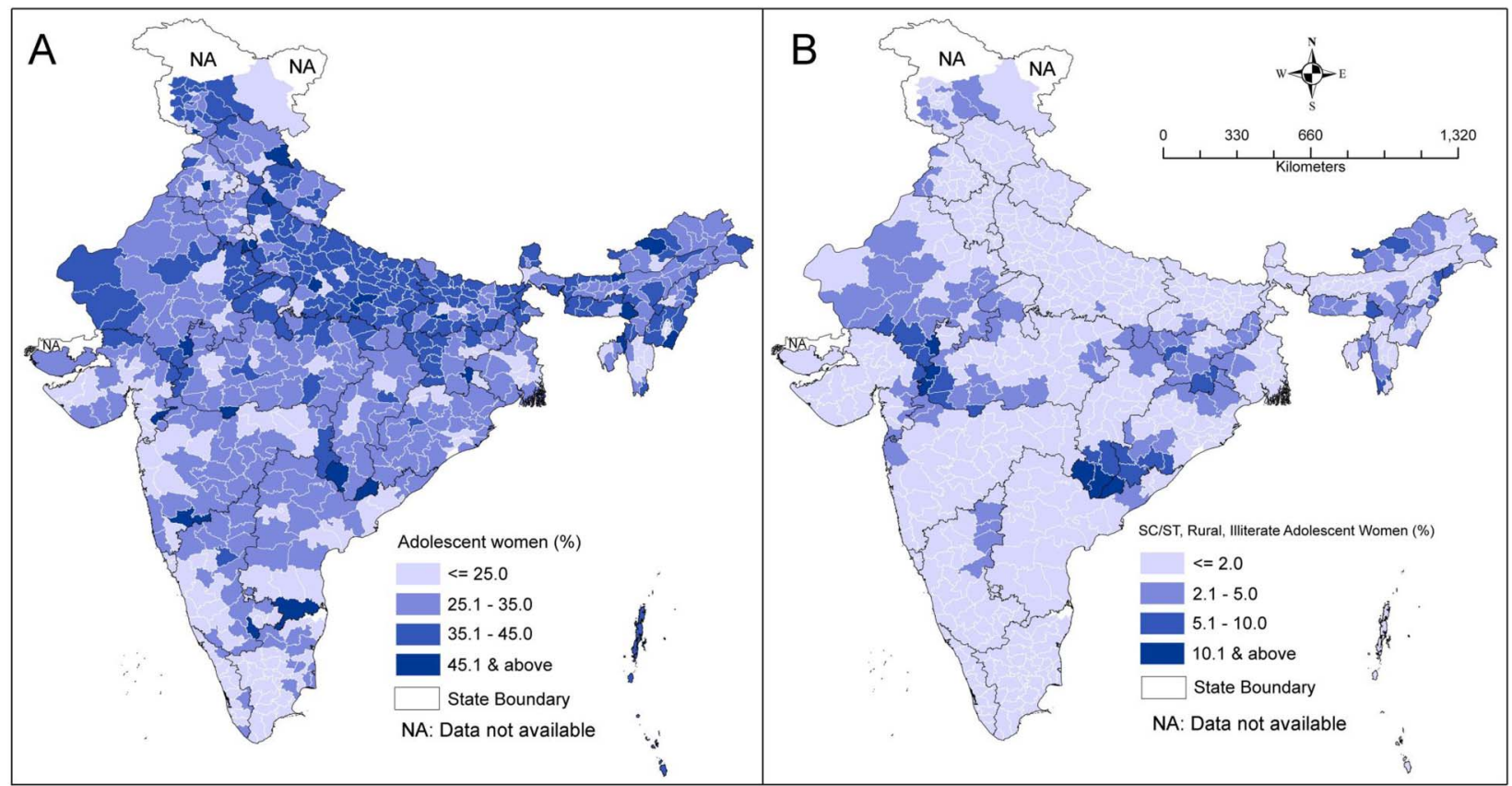

Figure 2 (A) District-wise proportion of adolescent women out of total women in reproductive age, India, 2011; and (B) district-wise proportion of rural, illiterate Scheduled Castes (SC)/Scheduled Tribes (ST) adolescent women out of total rural women in reproductive age, India, 2011. 


\section{Limitations of the study}

Among the major limitations of this study, the first is the use of relatively old data sets. However, in order to assess the trends in disparity among socioeconomic groups, it was critical to use data from the three available NFHS. Unfortunately, the quinquennial canvassing of the NFHS was discontinued after the third wave of the survey. The fourth wave of the NFHS is expected to be released shortly. Second, the selection of the child sample of the adolescent mothers belonging to different socioeconomic groups might not be nationally representative, as the sampling of the NFHS does not provide specific consideration of each age group of women across different socioeconomic groups. Third, the reporting of the status of full vaccination could be affected by recall errors of mothers (respondents of the survey). As far as relevance of this study in the present time is concerned, it has provided statistics from the recent surveys of no remarkable change in the immunisation pattern, especially in some parts of the country, and the study argues that socioeconomic disparity in the utilisation pattern has a persistent and long-term impact on Indian society.

\section{Conclusion}

This study based on empirical analysis underscores insufficient improvement in provision of full immunisation to Indian children, especially to children born to adolescent mothers, over one and a half decades. Highlighting the influence of select socioeconomic indicators, the study presented twofold to threefold difference in the probabilities of children of adolescent mothers availing full immunisation between the least and the most advantaged groups of the population. The study strongly advocates for the promotion of a comprehensive scheme focusing on adolescent mothers and their children to improve levels of full immunisation while minimising the social disparities in the overall coverage. The geographical concentration of adolescent women out of all women of reproductive age, and those belonging to deprived groups, presented in this study would help policymakers to prioritise the intervention in health programmes including immunisation.

\section{Author affiliations \\ ${ }^{1}$ Department of Geography, School of Earth Sciences, Central University of Karnataka, Kalaburagi, Karnataka, India \\ ${ }^{2}$ Population Health \& Nutrition Research Program, Institute for Human Development, New Delhi, Delhi, India \\ ${ }^{3}$ National Institute of Medical Statistics, Indian Council of Medical Research, New Delhi, Delhi, India \\ ${ }^{4}$ Society for Health and Demographic Surveillance, Suri, West Bengal, India}

Acknowledgements The authors acknowledge the editor and three anonymous reviewers for their comments and constructive suggestions, which helped them to improve the earlier version of this paper.

Funding This research received no specific grant from any funding agency in the public, commercial or not-for-profit sectors.
Competing interests During the preparation of this manuscript, PKS was Post-Doctoral Fellow at the Max Planck Institute for Demographic Research (MPIDR), Rostock, Germany.

Ethics approval This study used data available in the public domain for use by researchers on a granted request from the DHS programme (http://www. dhsprogram.com).

Provenance and peer review Not commissioned; externally peer reviewed.

Data sharing statement No additional data are available.

Open Access This is an Open Access article distributed in accordance with the Creative Commons Attribution Non Commercial (CC BY-NC 4.0) license, which permits others to distribute, remix, adapt, build upon this work noncommercially, and license their derivative works on different terms, provided the original work is properly cited and the use is non-commercial. See: http:// creativecommons.org/licenses/by-nc/4.0/

\section{REFERENCES}

1. WHO. Global routine vaccination coverage, 2011. Wkly Epidemiol Rec 2012;87:432-6.

2. Population Reference Bureau. Child mortality decreases globally and immunization coverage increases, despite unequal access, 2009. http://www.prb.org/Publications/Articles/2009/childmortality. aspx (accessed 5 Nov 2015).

3. Kumar C, Singh PK, Rai RK. Under-five mortality in high focus states in India: a district level geospatial analysis. PLOS ONE 2012;7:e37515.

4. Kumar C, Singh PK, Rai RK. Coverage gap in maternal and child health services in India: assessing trends and regional deprivation during 1992-2006. J Public Health (Oxf) 2013;35:598-606.

5. Savy M, Edmond K, Fine PE, et al. Landscape analysis of interactions between nutrition and vaccine responses in children. J Nutr 2009;139:2154S-218S.

6. UNICEF. The situation of children in India: a profile, 2011. https:// www.google.com/url?sa=t\&rct=j\&q=\&esrc=s\&source=web\& $c d=4 \& c a d=r j a \& v e d=0 C D s Q F j A D \& u r l=h t t p \% 3 A \% 2 F \% 2 F w w w$. unicef.org\%2Fsitan\%2Ffiles\%2FSitAn_India_May_2011. pdf\&ei=pUVZUqHbGcmZiAeH-YHYDg\&usg=AFQjCNFzWIAOsoy OIW2v Gz1Atrj678IA\&bvm=bv.53899372,d.aGc

7. Government of India. Millennium Development Goals India Country Report. New Delhi: Social Statistics Division, Ministry of Statistics and Planning Division, Government of India, 2015.

8. Banerjee AV, Duflo E, Glennerster R, et al. Improving immunisation coverage in rural India: clustered randomised controlled evaluation of immunisation campaigns with and without incentives. BMJ 2010;340:c2220

9. Laxminarayan R, Ganguly NK. India's vaccine deficit: why more than half of Indian children are not fully immunized, and what can-and should-be done. Health Aff (Millwood) 2011;30:1096-103.

10. WHO. Progress in global control and regional elimination of measles, 2000-2011. Wkly Epidemiol Rec 2013;88:29-36.

11. WHO. Tracking progress towards global polio eradication, 20112012. Wkly Epidemiol Rec 2013;88:153-60.

12. IIPS. District level household and facility survey, 2007-08: India. Mumbai: International Institute for Population Sciences (IIPS), 2010.

13. Travasso C. "Mission Indradhanush" targets India's unvaccinated children. BMJ 2015;350:h1688.

14. World Population Day. Spotlight on adolescent pregnancy, 2013. https://www.google.com/url?sa=t\&rct=j\&q=\&esrc=s\&source=web\& $\mathrm{cd}=1 \& \mathrm{cad}=\mathrm{rja} \& \mathrm{ved}=0 \mathrm{CCgQFjAA \& url}=\mathrm{http} \% 3 \mathrm{~A} \% 2 \mathrm{~F} \% 2 \mathrm{Fwww} . \mathrm{unf}_{\mathrm{f}}$ org $\% 2 F$ webdav\%2Fsite $\% 2 F$ global\%2Fshared\%2Fwpd $2013 \%$ 2Fwpd_2013_Global_posters.pdf\&ei=u05YUsvdHOjYigeltICYBg\& usg=AFQjCNFY05t_VvTyci86qRgrSsrSzQ4RNA\&bvm=bv. 53899372,d.aGc

15. Fatusi AO, Hindin MJ. Adolescents and youth in developing countries: health and development issues in context. J Adolesc 2010;33:499-508.

16. Klingberg-Allvin M, Graner S, Phuc HD, et al. Pregnancies and births among adolescents: a population-based prospective study in rural Vietnam. Sex Reprod Healthc 2010;1:15-19.

17. Omar K, Hasim S, Muhammad NA, et al. Adolescent pregnancy outcomes and risk factors in Malaysia. Int J Gynaecol Obstet 2010;111:220-3. 
18. Rasheed S, Abdelmonem A, Amin M. Adolescent pregnancy in Upper Egypt. Int J Gynaecol Obstet 2011;112:21-4.

19. Lassi ZS, Salam RA, Das JK, et al. An unfinished agenda on adolescent health: opportunities for interventions. Semin Perinatol 2015;395:353-60

20. Boerma JT, Sommerfelt AE, Rutstein SO, et al. Immunization: levels, trends and differentials. Columbia, MD: Institute for Resource Development/Macro Systems, 1990.

21. LeGrand TK, Mbacké CS. Teenage pregnancy and child health in urban Sahel. Stud Fam Plann 1993;24:137-49.

22. Singh L, Rai RK, Singh PK. Assessing the utilization of maternal and child health care among married adolescent women: evidence from India. J Biosoc Sci 2012;44:1-26.

23. WHO. A conceptual framework for action on the social determinants of health. Discussion paper for the commission on social determinants of health. Geneva: Department of Equity, Poverty and Social Determinants of Health, Evidence and Information for Policy Cluster, World Health Organization, 2007.

24. Mackenbach JP, Bakker MJ; European Network on Interventions and Policies to Reduce Inequalities in Health. Tackling socioeconomic inequalities in health: analysis of European experiences. Lancet 2003;362:1409-14.

25. Drever $\mathrm{F}$, Whitehead M eds,. Health inequalities. London: The Stationery Office, 1997.

26. Singh GK, Yu SM. Adverse pregnancy outcomes: differences between U.S.-and foreign-born women in major U.S. racial and ethnic groups. Am J Public Health 1996;86:837-43.

27. Adler NE, Boyce T, Chesney MA, et al. Socioeconomic status and health: the challenge of the gradient. Am Psychol 1994;49:15-24.

28. Phelan JC, Link BG, Tehranifar P. Social conditions as fundamental causes of health inequalities: theory, evidence, and policy implications. J Health Soc Behav 2010;51(Suppl):S28-40.

29. Antonovsky A. Social class, life expectancy, and overall mortality. Milbank Mem Fund Q 1967;45:31-73.

30. Subramanian SV, Ackerson LK, Subramanyam MA, et al. Health inequalities in India: the axes of stratification. Brown J World Aff 2008;14:127-39.

31. Subramanian SV, Nandy S, Irving M, et al. The mortality divide in India: the differential contributions of gender, caste, and standard of living across the life course. Am J Public Health 2006;96:818-25.

32. Subramanian SV, Davey Smith G, Subramanyam M. Indigenous health and socioeconomic status in India. PLoS Med 2006;3:e421.

33. Balarajan $\mathrm{Y}$, Selvaraj S, Subramanian SV. Health care and equity in India. Lancet 2011;377:505-15.

34. Subramanyam MA, Kawachi I, Berkman LF, et al. Is economic growth associated with reduction in child undernutrition in India? PLoS Med 2011;8:e1000424.

35. Kumar C, Singh PK, Rai RK, et al. Early neonatal mortality in India, 1990-2006. J Community Health 2013;38:120-30.

36. Wagstaff A. Poverty and health sector inequalities. Bull World Health Organ 2002;80:97-105.

37. Raj A, Saggurti N, Balaiah D, et al. Prevalence of child marriage and its effect on fertility-control outcomes of young women in India: a cross-sectional, observational study. Lancet 2009;373:1883-9.

38. Paul VK, Sachdev HS, Mavalankar D, et al. Reproductive health, and child health and nutrition in India: meeting the challenge. Lancet 2011;377:332-49.

39. Singh PK, Rai RK, Alagarajan M, et al. Determinants of maternity care services utilization among married adolescents in rural India. PLOS ONE 2012;7:e31666

40. Raj A, Saggurti N, Lawrence D, et al. Association between adolescent marriage and marital violence among young adult women in India. Int J Gynecol Obstet 2010;110:35-9.

41. Becker S, Peters DH, Ronald HG, et al. The determinants of use of maternal and child health services in metro Cebu, the Philippines. Health Transit Rev 1993;3:77-89.

42. Warren CW, Monteith RS, Johnson JT, et al. Use of maternal-child health services and contraception in Guatemala and Panama. J Biosoc Sci 1987:19:229-43.

43. Cleland J. The benefits of educating women. Lancet 2010;376:933-4.

44. Gakidou E, Cowling K, Lozano R, et al. Increased educational attainment and its effect on child mortality in 175 countries between 1970 and 2009: a systematic analysis. Lancet 2010;376:959-74

45. Ozaltin E, Hill K, Subramanian SV. Association of maternal stature with offspring mortality, underweight, and stunting in low- to middle-income countries. JAMA 2010;303:1507-16.

46. Cleland JG, Van Ginneken JK. Maternal education and child survival in developing countries: the search for pathways of influence. Soc Sci Med 1988;27:1357-68.
47. Boyle MH, Racine Y, Georgiades $\mathrm{K}$, et al. The influence of economic development level, household wealth and maternal education on child health in the developing world. Soc Sci Med 2006;63:2242-54.

48. Caldwell JC. Education as a factor in mortality decline: an examination of Nigerian data. Popul Stud 1979;33:395-413.

49. Desai S, Alva S. Maternal education and child health: is there a strong causal relationship? Demography 1998;35:71-81.

50. Glewwe P. Why does mother's schooling raise child health in developing countries? Evidence from Morocco. J Hum Resources 1999;34:124-59.

51. Vikram K, Vanneman R, Desai S. Linkages between maternal education and childhood immunization in India. Soc Sci Med 2012;75:331-9.

52. Amin R, Li Y. NGO-promoted women's credit program, immunization coverage, and child mortality in rural Bangladesh. Women Health 1997;25:71-87.

53. Babalola S. Determinants of the uptake of the full dose of diphtheria-pertussis-tetanus vaccines (DPT3) in Northern Nigeria: a multilevel analysis. Matern Child Health J 2009;13:550-8.

54. Jamil K, Bhuiya A, Streatfield K, et al. The immunization programme in Bangladesh: impressive gains in coverage, but gaps remain. Health Policy Plan 1999;14:49-58.

55. Joshi AR. Maternal schooling and child health: preliminary analysis of the intervening mechanisms in rural Nepal. Health Transit Rev 1994:4:1-28.

56. Steele F, Diamond I, Amin S. Immunization uptake in rural Bangladesh: a multilevel analysis. J R Stat Soc 1996;159:289-99.

57. LeVine RA, LeVine SE, Schnell B. "Improve the women": mass schooling, female literacy and worldwide social change. Harv Educ Rev 2001;71:1-51.

58. Basu AM. Culture, the status of women and demographic behaviour: illustrated with the case of India. Oxford: Clarendon Press, 1992.

59. Das Gupta M. Death clustering, mother's education and the determinants of child mortality in rural Punjab, India. Popul Stud 1990;44:489-505.

60. Caldwell JC, McDonald P. Influence of maternal education on infant and child mortality: levels and causes. Health Policy Educ 1982;2:251-67.

61. Pebley AR, Goldman N, Rodríguez G. Prenatal and delivery care and childhood immunization in Guatemala: do family and community matter? Demography 1996;33:231-47.

62. Basu K, Narayan A, Ravallion M. Is knowledge shared within households? World Bank Policy Research Working Papers Series $1999 ; 2261$

63. Office of the Registrar General and Census Commissioner. Census Atlas of India, 2001. New Delhi: Office of the Registrar General and Census Commissioner, India, Ministry of Home Affairs, 2008.

64. Dettrick Z, Jimenez-Soto E, Hodge A. Socioeconomic and geographical disparities in under-five and neonatal mortality in Uttar Pradesh, India. Matern Child Health J 2014;18:960-9.

65. International Institute for Population Sciences (IIPS) and Macro International. National Family Health Survey (NFHS-3), 2005-06: India, 2007.

66. International Institute for Population Sciences (IIPS) and Macro International. National Family Health Survey (NFHS-2), 1998-99: India, 2000.

67. International Institute for Population Sciences (IIPS) and Macro International. National Family Health Survey ( $\mathrm{MCH}$ and family Planning) 1992-93, India, 1995.

68. Saroha E, Altarac M, Sibley LM. Caste and maternal health care service use among rural Hindu women in Maitha, Uttar Pradesh, India. J Midwifery Womens Health 2008;53:e41-7.

69. Michele G, Shekar M, Das Gupta M, et al. India's undernourished children: a call for reform and action. Health, Nutrition, and Population Discussion Papers, Washington, DC: World Bank, 2005.

70. Datar A, Mukherji A, Sood N. Health infrastructure \& immunization coverage in rural India. Indian J Med Res 2007;125:31-42.

71. Deaton A, Dreze J. Poverty and inequality in India: a re-examination. Econ Political Wkly 2002;37:3729-48.

72. Sen A, Himanshu. Poverty and inequality in India-I. Econ Political Wkly 2004;39:4247-63.

73. Dev SM, Ravi C. Poverty and inequality: all-India and states, 19832005. Econ Political Wkly 2007;42:509-21.

74. Cain JS, Hasan R, Magsombol R, et al. Accounting for inequality in India: evidence from household expenditures. World Dev 2010;38:282-97.

75. Sen A, Himanshu. Poverty and inequality in India: getting closer to the truth. Deaton A, Kozel V, eds. The great Indian poverty debate. New Delhi: Macmillan, 2005. 
76. Pattanaik F, Nayak NC. Trends and forecasting of employment intensity of growth in India. J Asia Pac Economy 2013;18: 438-59.

77. OECD. Special focus: inequality in emerging economies (EEs). 2011. http://www.oecd.org/dataoecd/40/13/49170475.pdf

78. Chalasani S, Rutstein S. Household wealth and child health in India. Popul Stud (Camb) 2014;68:15-41.

79. Chalasani S. Understanding wealth-based inequalities in child health in India: a decomposition approach. Soc Sci Med 2012;75:2160-9.

80. Pal S. An analysis of childhood malnutrition in rural India: role of gender, income and other household characteristics. World Dev 1999;27:1151-71

81. Subramanyam MA, Kawachi I, Berkman LF, et al. Socioeconomic inequalities in childhood undernutrition in India: analyzing trends between 1992 and 2005. PLoS ONE 2010;5:e11392.

82. Kanjilal B, Mazumdar PG, Mukherjee M, et al. Nutritional status of children in India: household socio-economic condition as the contextual determinant. Int J Equity Health 2010;9:19.

83. Singh PK, Rai RK, Kumar C. Equity in maternal, newborn, and child health care coverage in India. Glob Health Action 2013;6:22217.

84. Fosu GB. Childhood morbidity and health services utilization: cross-national comparisons of user-related factors from DHS data. Soc Sci Med 1994;38:1209-20.

85. Baru R, Acharya A, Acharya S, et al. Inequities in access to health services in India: caste, class and region. Econ Political Wkly 2010;55:49-58.

86. Bonu S, Bhushan I, Rani M, et al. Incidence and correlates of 'catastrophic' maternal health care expenditure in India. Health Policy Plan 2009;24:445-56.

87. Roy K, Howard DH. Equity in out-of-pocket payments for hospital care: evidence from India. Health Policy 2007;80: 297-307.

88. Wang L. Determinants of child mortality in LDCs: empirical findings from demographic and health surveys. Health Policy 2003;65:277-99.

89. Arokiasamy P, Gautam A. Neonatal mortality in the empowered action group states of India: trends and determinants. J Biosoc Sci 2008;40:183-201.

90. Baqui $\mathrm{AH}$, Williams EK, Darmstadt GL, et al. Newborn care in rural Uttar Pradesh. Indian J Pediatr 2007;74:241-7.

91. Pallikadavath S, Foss M, Stones RW. Antenatal care: provision and inequality in rural north India. Soc Sci Med 2004;59: 1147-58.

92. Montgomery MR, Hewett PC. Urban poverty and health in developing countries: household and neighbourhood effects. Demography 2005;42:397-425.

93. Islam M, Montgomery M, Taneja S. Urban health and care seeking behaviour: a case study of slums in India and the Philippines. Bethesda, MD, USA: The Partners for Health Reform Project, Abt Associates Inc, 2006.
94. Fotso JC, Ezeh A, Oronje R. Provision of use of maternal health services among urban poor women in Kenya: what do we know and what can we do? J Urban Health 2008;85:428-42.

95. WHO. Postpartum care of the mother and newborn: a practical guide. Geneva, Switzerland: Maternal and Newborn Health/Safe Motherhood Unit, Division of Reproductive Health (Technical Support), 1998

96. Kesteron AJ, Cleland J, Sloggett A, et al. Institutional delivery in rural India: the relative importance of accessibility and economic status. BMC Pregnancy Childbirth 2010;10:30.

97. Bhatia J, Cleland J. Determinants of maternal care in a region of South India. Health Transition Rev 1995;5:127-42.

98. UNICEF. The state of the World's children 1998. New York: Oxford University Press (for UNICEF), 1998.

99. Filmer D, Pritchett LH. Estimating wealth effects without expenditure data-or tears: an application to educational enrollments in states of India. Demography 2001;38:115-32.

100. Rutstein SO, Johnson K. The DHS Wealth Index. DHS comparative reports no. 6. Calverton, MD, USA: ORC Macro; Measure DHS, 2004.

101. Howe LD, Hargreaves JR, Gabrysch S, et al. Is the wealth index a proxy for consumption expenditure? A systematic review. $J$ Epidemiol Community Health 2009;63:871-7.

102. Armitage P, Berry G, Matthews JNS. Statistical methods in medical research. 4th edn. Oxford, UK: Blackwell Science, 2002.

103. Rao JNK, Scott AJ. On chi-square tests for multiway contingency tables with cell proportions estimated from survey data. Ann Stat 1984;12:46-60.

104. Rammohan A, Awofeso N. District-level variations in childhood immunizations in India: the role of socio-economic factors and health infrastructure. Soc Sci Med 2015;145:163-72.

105. Singh PK. Trends in child immunization across geographical regions in India: focus on urban-rural and gender differentials. PLOS ONE 2013;8:e73102.

106. Fay M, Leipziger $\mathrm{D}$, Wodon $\mathrm{Q}$, et al. Achieving child health related Millennium Development Goals: the role of infrastructure. World Dev 2005;33:1267-84.

107. Lloyd CB, Mensch BS. Marriage and childbirth as factors in school exit: an analysis of DHS data from sub-Saharan Africa. Policy Research Division Working Paper No. 219. New York: Population Council, 2006

108. Jensen $\mathrm{R}$, Thornton $\mathrm{R}$. Early female marriage in the developing world. Gend Dev 2002;11:9-19.

109. Kruk ME, Prescott MR, de Pinho $\mathrm{H}$, et al. Equity and the child health Millennium Development Goal: the role of pro-poor health policies. J Epidemiol Community Health 2011;65:327-33.

110. Parkhurst JO, Ssengooba F. Assessing access barriers to maternal health care: measuring bypassing to identify health centre needs in rural Uganda. Health Policy Plan 2009;24:377-84.

111. Registrar General and Census Commissioner. Annual Health Survey 2012-13 Fact Sheet. New Delhi: Ministry of Home Affairs, Government of India. http://www.censusindia.gov.in 